\title{
Climatological features of electron density in the polar ionosphere from long-term observations of EISCAT/ESR radar
}

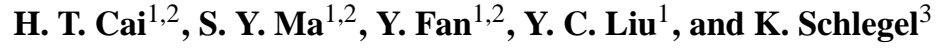 \\ ${ }^{1}$ School of Electronics Information, Wuhan University, 430079, China \\ ${ }^{2}$ Key Lab of Geospace Environment and Geodesy, CNEM \\ ${ }^{3}$ Max Planck Institute for Solar System Research(MPS), 37191 Katlenburg-Lindau, Germany
}

Received: 17 October 2006 - Revised: 15 November 2007 - Accepted: 4 December 2007 - Published: 2 January 2008

\begin{abstract}
In this paper, climatological features of the polar F2-region electron density $\left(N_{e}\right)$ are investigated by means of statistical analysis using long-term observations from the European Incoherent Scatter UHF radar (called EISCAT in the following) and the EISCAT Svalbard radar (ESR) during periods of quiet to moderate geomagnetic activity. Fieldaligned measurements by the EISCAT and ESR radars operating in CP-1 and CP-2 modes are used in this study, covering the years 1988-1999 for EISCAT and 1999-2003 for ESR. The data are sorted by season (equinox, summer and winter) and solar cycle phase (maximum, minimum, rising and falling). Some novel and interesting results are presented as follows: (1) The well-known winter anomaly is evident during the solar maximum at EISCAT, but it dies out at the latitude of the ESR; (2) The daytime peaks of $N_{e}$ at EISCAT for all seasons during solar maximum lag about $1-2 \mathrm{~h}$ behind those at ESR, with altitudes about 10-30 km lower. (3) In addition to the daytime peak, it is revealed that there is another peak just before magnetic midnight at ESR around solar maximum, especially in winter and at equinox. The daytime ionization peak around magnetic noon observed by ESR can be attributed to soft particle precipitation in the cusp region, whereas the pre-midnight $N_{e}$ maximum seems likely to be closely related to substorm events which frequently break out during that time sector, in particular for the winter case. (4) Semiannual variations are found at EISCAT during solar minimum and the falling phase of the solar cycle; at the rising phase, however, the EISCAT observations show no obvious seasonal variations.
\end{abstract}

Keywords. Ionosphere (Particle precipitation; Plasma convection; Polar ionosphere)

\footnotetext{
Correspondence to: $\mathrm{H}$. T. Cai

(htcai@whu.edu.cn)
}

\section{Introduction}

The Earth's ionosphere is formed by the ionization of the atmosphere, owing to the solar EUV and X-ray radiations and, mainly for the high-latitudes, by energetic particles impinging on the atmosphere from the magnetosphere. Once formed, the ionized particles of ionospheric plasma are affected by numerous processes, including chemical reactions and various transport due to neutral wind, electric and magnetic fields, etc. The ionosphere is coupled closely with both the magnetosphere and the thermosphere in which the ionosphere is immersed. These lead the ionosphere to vary significantly with solar cycle, season, local time, and geomagnetic activity. The background characteristics of ionospheric electron density are of basic importance in understanding and forecasting space weather.

Electron density variations of the mid- and low-latitude ionospheric F2-layer have been extensively investigated, and a number of anomalies, such as the winter anomaly and the semiannual anomaly, have been reported (Yonezawa and Arima, 1959; Yonezawa, 1971). A number of possible causes have been proposed for these anomalies, as reviewed by Rishbeth (1998). The best-accepted mechanism is the chemical explanation suggested by Rishbeth and Setty (1961). Millward et al. (1996) modeled the semiannual variation, confirming the role of the chemical composition changes. Recently, using ionosonde data, Rishbeth et al. (2000b) studied the semiannual and annual variations of the ionospheric F2-peak at middle and low latitudes. They found that $H_{m} F_{2}$ has a well-defined relationship with solar activity. Zou et al. (2000) numerically investigated the annual, seasonal and semiannual variation of the F2-layer electron density under geomagnetically quiet conditions, and claimed that the noon $N_{m} F_{2}$ is closely related to the ambient atomic/molecular concentration ratio. Rishbeth et al. (2000a) highlighted the role of global-scale thermospheric motions, which produce the composition changes, in the

Published by Copernicus Publications on behalf of the European Geosciences Union. 


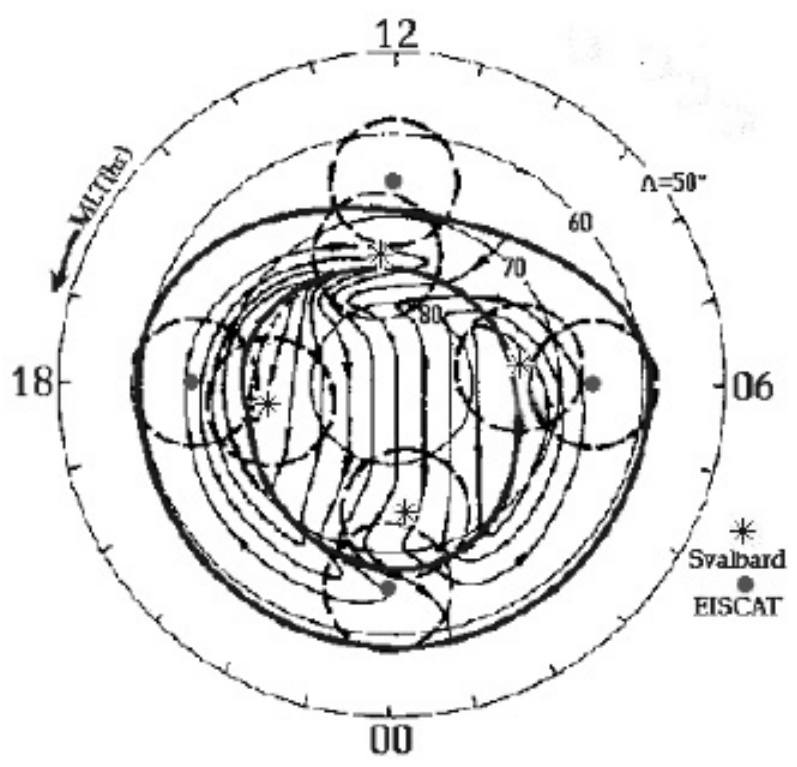

Fig. 1. The position of EISCAT/ESR radar in relation to with the auroral ellipse and polar cap. (The solid points represent the location of EISCAT; asterisks for the ESR, and the two thick black ellipse lines imply the boundaries of the auroral oval during lower geomagnetic activity).

formation of seasonal and semiannual effects in the midlatitude F2-layer.

As the aforementioned anomalies are frequently observed at mid- and low-latitudes, they were thought to die away at latitudes higher than $60^{\circ}$. Baron and Wand (1983a), however, reported these anomalies in Alaska $\left(65.1^{\circ} \mathrm{N}\right)$ on the basis of the Chatanika incoherent radar observations. A couple of years later, the winter anomaly at Troms $\phi\left(69.6^{\circ} \mathrm{N}\right.$, $19.2^{\circ} \mathrm{E}$ ) was reported by Farmer et al. (1990). Liu (2001) investigated the climatological features of the high-latitude ionosphere using several years of EISCAT/ESR observations, but her research was only carried out in terms of two characteristic parameters, namely, the ionospheric F2-layer electron density peak, $N_{m} F_{2}$, and the corresponding altitude, $H_{m} F_{2}$. In the Southern Hemisphere, Zhu et al. (1996, 1998) reported the existence of an F-region winter anomaly over Zhongshan Station $\left(77.1^{\circ} \mathrm{S}\right)$, based on ionosonde data around solar maximum (1990-1991). Low energy particle precipitation was proposed to be a possible cause of the ionospheric F-region $N_{e}$ peak around magnetic noon. By analyzing observations from the same station, Shen et al. (2003) claimed that there is no winter anomaly around solar minimum, and highlighted the role of magnetospheric particle precipitation in the formation of ionization enhancements around magnetic noon. The seasonal features of averaged ionospheric $N_{e}$ based on long-term observations at high latitudes, resulting in particular from the polar cusp/cap regions, are not as well reported in the literature.
In both hemispheres, there are funnel-shaped areas with near zero magnetic field magnitude but dense plasma, which are called the polar cusps or clefts. In these regions, solar plasma has direct access to the upper atmosphere. They provide an entry for particles from the solar wind and magnetosphere into near-Earth geospace without crossing geomagnetic field lines. The unique configuration of the geomagnetic field at polar cusps makes them among the most popular regions for research into the geospace environment. Generally, the cusp regions lie around $\pm 78^{\circ}$ MLAT, with about $5^{\circ}$ extension in latitude. The ESR is located close to Longyearbyen on the island of Spitsbergen. The position of the EISCAT and the ESR in relation to the auroral oval and polar cap is shown in Fig. 1. It can be seen that EISCAT radar lies in the auroral oval for most of the time. The ESR radar, however, lies in the vicinity of the cusp region during the daytime and within the polar cap during the nighttime. The specific locations and powerful capabilities of these two radars provide an excellent opportunity for comparative studies of polar ionospheric characteristics, especially in the auroral oval and polar cusp/cap regions.

The EISCAT radar $\left(69.6^{\circ} \mathrm{N}, 19.2^{\circ} \mathrm{E}\right)$ began taking data in 1981 , while the ESR $\left(78^{\circ} \mathrm{N}, 16^{\circ} \mathrm{E}\right)$ began operations in 1996. Hence a relatively long period of ionospheric measurements have now been accumulated. In this paper, fieldaligned measurements from the EISCAT UHF radar during the 22nd solar cycle and from the ESR radar during the period of 1999-2003 are combined in a statistical study of the climatological characteristics of electron density in the polar ionospheric F2-layer.

\section{Data analysis}

Field-aligned measurements obtained from EISCAT Common Program One and Two (CP-1 and CP-2) during 19881999 and measurements from the ESR during 1999-2003 are used in this work. In order to eliminate the effects of extensive disturbances, only data with the maximum $K_{p} \leq 4$ are included. The annual averaged sunspot numbers during this period are shown in Fig. 2. According to the variations of averaged sunspot number, the period of selected ESR observations is around solar maximum. As for the EISCAT UHF data, the period of 1988-1999 can be divided into 4 phases: the rising phase (1988, 1998 and 1999), solar maximum (1989, 1990 and 1991), the falling phase (1992, 1993 and 1994) and solar minimum (1995, 1996 and 1997). Each phase is further divided into 3 seasons, namely the equinox, summer and winter. We do not distinguish spring and autumn seasons here because there are not enough observations to separate them statistically, especially for the falling phase of the solar cycle at EISCAT. The numbers of EISCAT/ESR radar observation events for each group are listed in Table 1 . The entries correspond to the number of time sequences of 
Table 1. Number of EISCAT/ESR radar observation events for each group.

\begin{tabular}{|c|c|c|c|c|c|}
\hline Seasons & \multicolumn{3}{|c|}{ EISCAT } & olar Min. & $\begin{array}{c}\text { ESR } \\
\text { Solar Max }\end{array}$ \\
\hline $\begin{array}{c}\text { Equinox } \\
\text { (Feb 5-May 4) } \\
\text { (Aug. 4-Nov. 5) }\end{array}$ & 25 & 14 & 6 & 12 & 150 \\
\hline $\begin{array}{c}\text { Summer } \\
\text { (May 5-Aug 4) }\end{array}$ & 12 & 8 & 10 & 11 & 30 \\
\hline $\begin{array}{c}\text { Winter } \\
\text { (Nov 5-Feb 4) }\end{array}$ & 8 & 12 & 11 & 15 & 105 \\
\hline
\end{tabular}

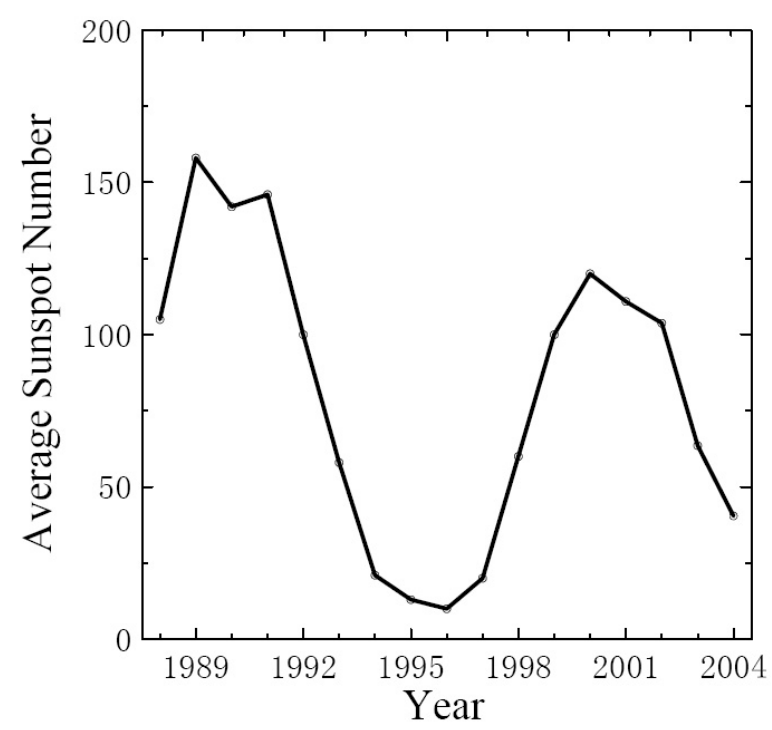

Fig. 2. Annual averaged sunspot number during 1988-2004.

successive measurements with lengths between 4 hours and one day, which have been used in the study.

Global-scale thermospheric motions have an important effect on the long-term variation of the F2-layer electron density (Rishbeth et al., 2000a), and Rishbeth (1998) has pointed out that thermospheric circulation may differ during quiet and disturbed times. Hence, it seems to be an oversimplification to assume that the daytime peak of electron density, $N_{m} F_{2}$, has no relation to geomagnetic activity, though Baron and Wand (1983b) claimed that there was no obvious relation between the nighttime $N_{m} F_{2}$ and the $K_{p}$ index. Therefore, only data obtained under quiet to moderate geophysical conditions are chosen in our study to eliminate variations caused by extensive disturbances. This is different from the philosophy employed by Farmer et al. (1990), where measurements made under all conditions were used.
The signal-to-noise ratio (SNR) indicates the reliability of the data and is therefore important in the analysis. Unreliable observations are eliminated according to the quality of data fitting. Since the input data come from several different kinds of radar experiments, they usually have different time and range resolutions. For the convenience of analysis, a fixed 2-D grid has been specified, with resolutions of $10 \mathrm{~km}$ in range and $10 \mathrm{~min}$ in UT time. A linear interpolation method is employed to project all the data sets onto the aforementioned fixed grid. The resulting data sets are binned by height ( $H$, every $10 \mathrm{~km})$, hour of day (UT, every $10 \mathrm{~min})$, and season of year $(S)$. A sequence of $N_{e}$ measurements representing the same conditions can be obtained by collecting all observations falling into the same bin. Within each bin, the final "mean" electron density is defined as the median value of the corresponding electron density sequence:

$\left\langle N_{e}(H, U T, S)\right\rangle=\operatorname{Median}\left(\left\{N_{e} i(H, U T, S)\right\}\right)$,

where, $\left\{N_{e} i(H, U T, S)\right\}$ corresponds to the $N_{e}$ sequence obtained in the $(H, U T, S)$ bin. The standard deviation $\sigma$ is calculated by

$\sigma=\sqrt{\frac{\sum\left(\left\langle N_{e}(H, U T, S)\right\rangle-N_{e i}(H, U T, S)\right)^{2}}{N(H, U T, S)-1}}$,

where $N(H, U T, S)$ is the number of available data in the $(H, U T, S)$ bin, and plotted as an error bar on every 10th temporal grid points in the following figures. Since the $U T$ coverage of input data is uneven, $N(H, U T, S)$ varies in different bins. In most bins, $N(H, U T, S)$ is no less than 70 percent of the number of observation events. The worst cases appear around dawn and dusk at equinox of solar minimum, with $N(H, U T, S)$ being slightly higher than 30 percent of the total number of observation events. 

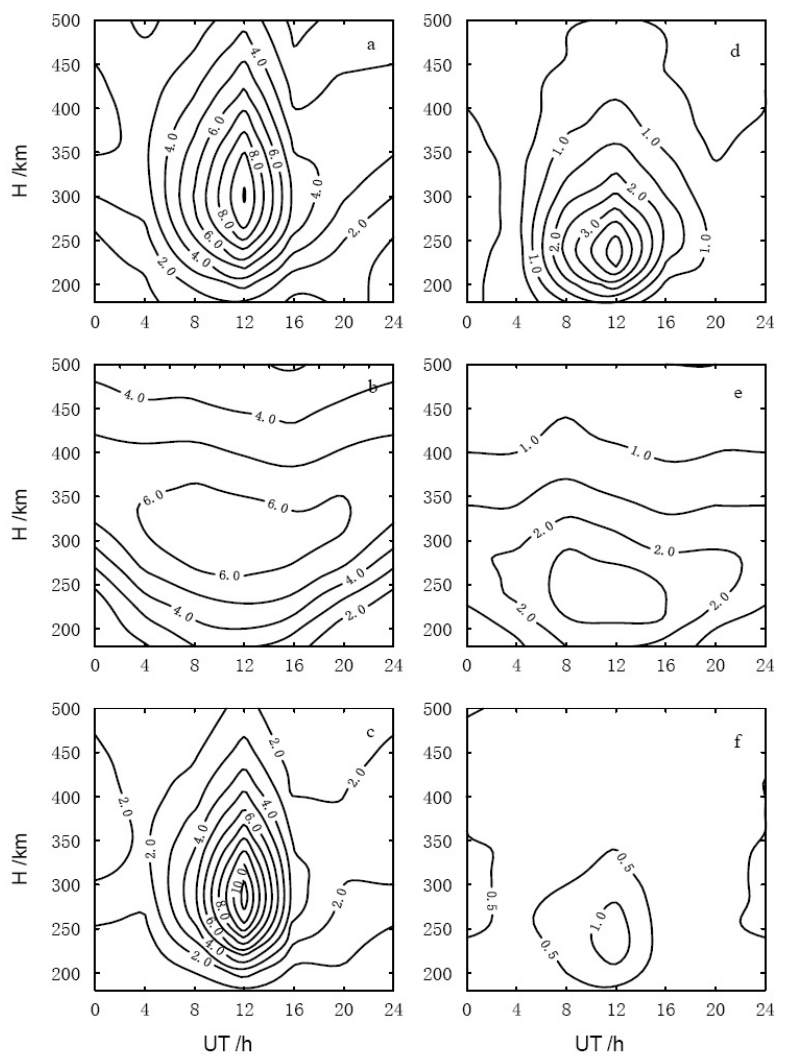

Fig. 3. 2-D distributions of mean $N_{e}$ versus $U T$ and height $H$ around solar maximum $(\mathbf{a}, \mathbf{b}$ and $\mathbf{c})$ and solar minimum $(\mathbf{d}, \mathbf{e}$ and $\mathbf{f})$. (top panel: equinox; middle panel: summer; bottom panel: winter) (units: $10^{11} \mathrm{~m}^{-3}$ ).

\section{Climatological characteristics of $N_{e}$}

\subsection{Statistical results from the EISCAT (1988-1999)}

\subsubsection{Results around solar maximum and minimum}

2-D distributions of mean $N_{e}$ vs. $U T$ and $H$ for the 3 seasons around solar maximum ( $3 \mathrm{a}, 3 \mathrm{~b}$ and $3 \mathrm{c}$ ) and solar minimum (3d, 3e and 3f) are shown in Fig. 3. Diurnal variations of $N_{e}$ at the altitudes of the F2-peak are plotted in Fig. 4 for solar maximum (4a, $4 \mathrm{~b}$ and $4 \mathrm{c}$, at $290 \mathrm{~km}$ ) and solar minimum (4d, $4 \mathrm{e}$ and $4 \mathrm{f}$, at $230 \mathrm{~km})$, respectively.

Around the solar maximum, $N_{e}$ in winter reaches a prominent peak of $11.5 \times 10^{11} \mathrm{~m}^{-3}$ at 11:40 UT (12:57 LT), at about $290 \mathrm{~km}$ altitude. Note that there is a slight decrease during 04:00-06:00 UT and also a slight increase during 18:00-22:00 UT. The maximum $N_{e}$ around equinox is $10.3 \times 10^{11} \mathrm{~m}^{-3}$ at 11:50 UT (13:07 LT). Compared to that in winter, the density peak at equinox is wider (in time), covering the range of 04:00-16:00 UT. $N_{e}$ near summer reaches a maximum of $6.7 \times 10^{11} \mathrm{~m}^{-3}$ at 09:50 UT (11:07 LT). The peak becomes wider between 04:00-20:00 UT, resulting in a
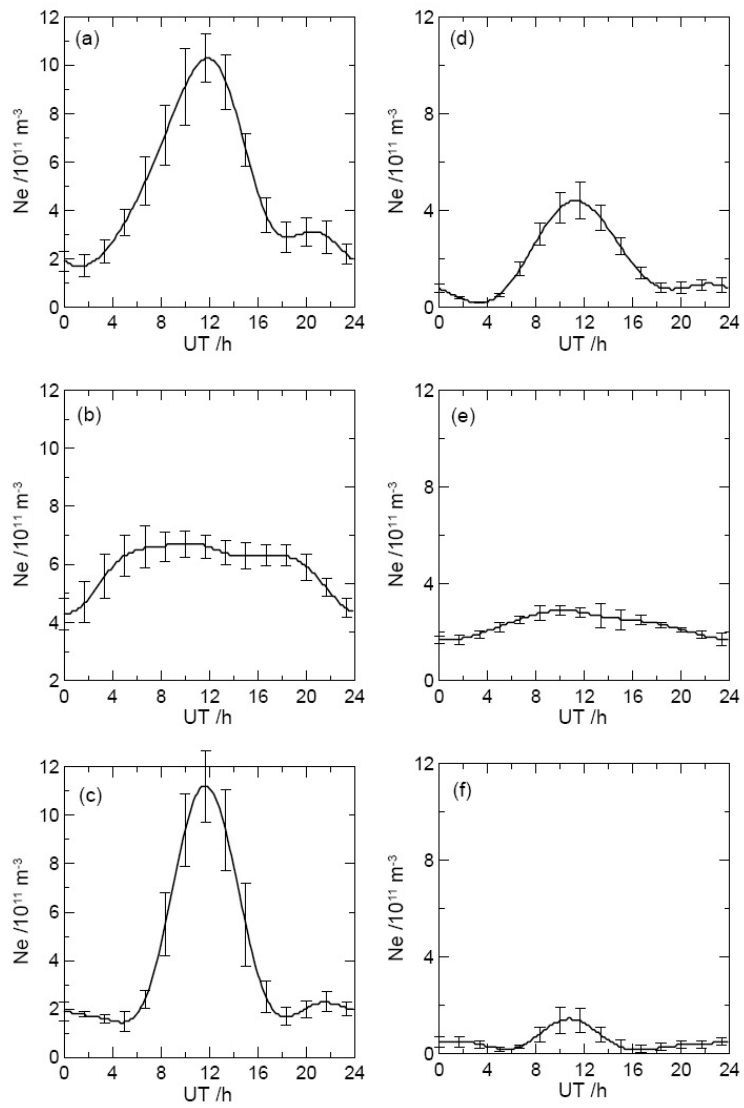

Fig. 4. Diurnal variation of mean $N_{e}$ at $290 \mathrm{~km}$ around solar maximum (a, b and $\mathbf{c})$ and at $230 \mathrm{~km}$ around solar minimum (d, e and f). (top panel: equinox; middle panel: summer; bottom panel: winter)(units: $10^{11} \mathrm{~m}^{-3}$ ).

smoother daily variation. It shows no sign of a minimum in the morning and evening sectors. The maximum electron density in winter is nearly twice as high as that in summer, exhibiting the manifestation of the well-known winter anomaly around solar maximum.

Around solar minimum, $N_{e}$ in winter is quite different from that around solar maximum. The maximum value is only $1.5 \times 10^{11} \mathrm{~m}^{-3}$ at 10:50 UT (12:07 LT). The diurnal variation is smooth throughout all UT times. $N_{e}$ at summer and equinox varies in a similar way to that near solar maximum, but with relatively lower values, $2.9 \times 10^{11} \mathrm{~m}^{-3}$ for summer and $4.5 \times 10^{11} \mathrm{~m}^{-3}$ for equinox. The higher density at equinox than in summer and winter demonstrates the existence of the semiannual anomaly at EISCAT latitudes around solar minimum.

Compared to solar maximum, the altitudes of the density peaks near solar minimum are about $60-70 \mathrm{~km}$ lower. 

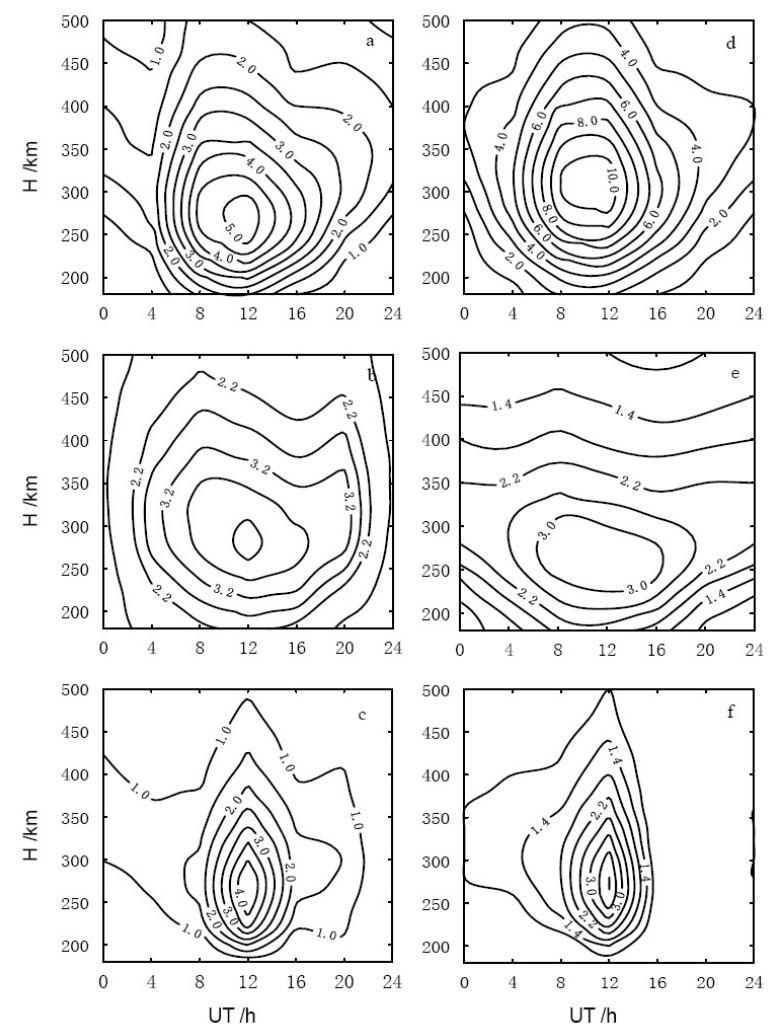

Fig. 5. The same as Figure 3, but for the rising (a, b and $\mathbf{c})$ and the falling (d, e and $\mathbf{f}$ ) phase of solar cycle. (top panel: equinox; middle panel: summer; bottom panel: winter) (units: $10^{11} \mathrm{~m}^{-3}$ ).

\subsubsection{Results at rising and falling phase}

Seasonal variations of $N_{e}$ exhibit quite different features in the rising and falling phases of the solar cycle. Mean 2-D distributions of $N_{e}$ vs. $U T$ and $H$ for the rising phase (5a, $5 \mathrm{~b}$ and $5 \mathrm{c}$ ) and falling phases (5d, 5e and 5f) are shown in Fig. 5. Corresponding diurnal variations at $270 \mathrm{~km}$ (at about the altitude of the F2-peak) are plotted in Fig. 6 for the rising (6a, $6 \mathrm{~b}$ and $6 \mathrm{c}$ ) and falling phase (6d, 6e and 6f), respectively.

During the rising phase of the 22 nd solar cycle, the maximum $N_{e}$ is $4.5 \times 10^{11} \mathrm{~m}^{-3}$ for winter, $4.8 \times 10^{11} \mathrm{~m}^{-3}$ for summer and $5.6 \times 10^{11} \mathrm{~m}^{-3}$ for equinox, exhibiting no obvious seasonal variations.

During the falling phase, however, $N_{e}$ exhibits quite different seasonal behaviors. At equinox, $N_{e}$ reaches a peak value of $11.0 \times 10^{11} \mathrm{~m}^{-3}$ at 10:50 UT (12:07 LT). Compared to the dramatic peak near equinox, the maximum $N_{e}$ near winter is much smaller, with a value of $4.0 \times 10^{11} \mathrm{~m}^{-3}$ at 11:10 UT (12:27 LT). The peak is confined in the range of 08:00-16:00 UT. $N_{e}$ near summer reaches a maximum of $3.4 \times 10^{11} \mathrm{~m}^{-3}$ at 11:00 UT (12:17 LT), with a smooth daily variation. The $N_{e}$ at equinox is more than 2 times higher than those in summer and/or winter, demonstrating obvious characteristics of the semiannual anomaly.
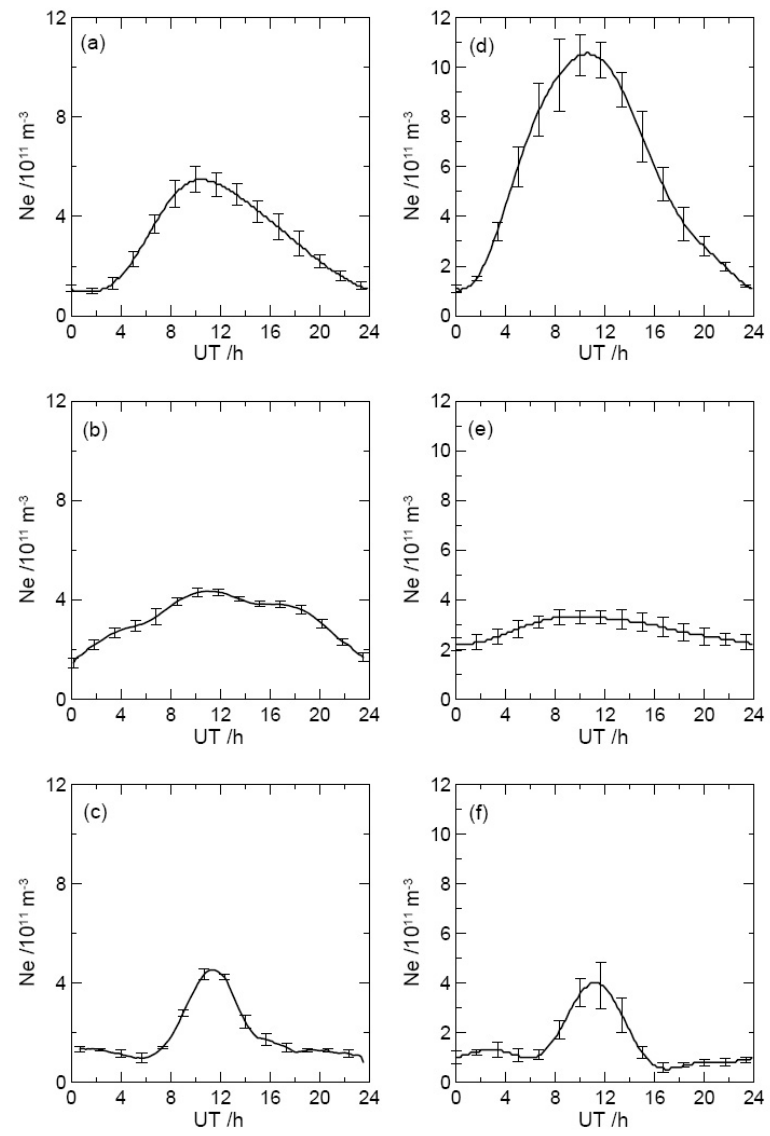

Fig. 6. The same as Fig. 4, but at $270 \mathrm{~km}$ for the rising (a, b and c) and the falling phase (d, e and $\mathbf{f}$ ) of solar cycle. (top panel: equinox; middle panel: summer; bottom panel: winter) (units: $10^{11} \mathrm{~m}^{-3}$ ).

\subsection{The ESR radar observations around solar maximum}

2-D mean $N_{e}$ distributions derived from the ESR data around solar maximum are shown in the left-hand column of Fig. 7a, b and c. Corresponding diurnal variations of $N_{e}$ at $310 \mathrm{~km}$ are shown in the right column (7d, 7e and 7f).

The variations of $N_{e}$ are quite different to those at Troms $\phi$ around solar maximum (Figs. 3a, b, c and $4 \mathrm{a}, \mathrm{b}, \mathrm{c}$ ). In winter, $N_{e}$ reaches a maximum value of $5.2 \times 10^{11} \mathrm{~m}^{-3}$ at 19:45 UT (22:35 MLT), with a minor peak at 09:20 UT (12:05 MLT). At equinox, $N_{e}$ reaches a prominent maximum of $8.7 \times 10^{11} \mathrm{~m}^{-3}$ at 09:40 UT (12:25 MLT), followed by a weaker but long-lasting peak around 18:00 UT (20:40 MLT). Note that the increase of $N_{e}$ before 09:00 UT is very fast. The summertime $N_{e}$ is about $4.0 \times 10^{11} \mathrm{~m}^{-3}$ before it starts to increase to $5.3 \times 10^{11} \mathrm{~m}^{-3}$ at 10:10 UT (12:30 MLT). The peak density is relatively unchanged up to 20:00 UT before $N_{e}$ drops gradually back to $4.0 \times 10^{11} \mathrm{~m}^{-3}$ at 22:00 UT.

Except for the pre-midnight peak, $N_{e}$ in winter is less than that in summer, demonstrating no sign of the so-called winter anomaly at the latitude of the ESR around solar maximum. 

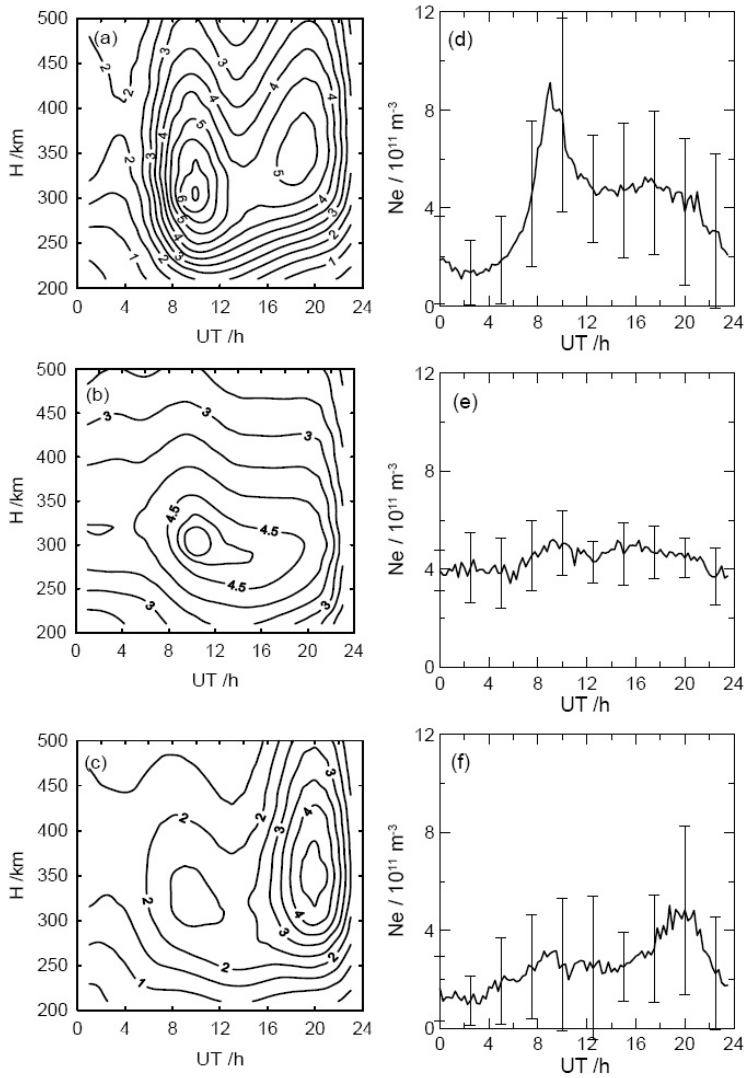

Fig. 7. Mean $N_{e}$ around solar maximum at the ESR site: 2-D distribution vs. $U T$ and $H$ (a, b and $\mathbf{c})$ and diurnal variations at $310 \mathrm{~km}$ (d, e and f). (top panel: equinox; middle panel: summer; bottom panel: winter) (units: $10^{11} \mathrm{~m}^{-3}$ ).

The altitude of the daytime $N_{e}$ peak at ESR is around $320 \mathrm{~km}$ for all seasons, about $10-30 \mathrm{~km}$ higher than that at the EISCAT site. Those for the minor peak at equinox and the maximum peak in winter before magnetic midnight are at about $350 \mathrm{~km}$, slightly higher than that during the daytime.

Note that the standard deviations of the ESR density estimates are appreciably larger than those at Troms $\phi$, implying larger day-to-day variations of the electron density. This may perhaps be related to the characteristic dynamic processes at the ESR latitude, which will be discussed in the following section.

\section{Discussion}

The aforementioned $N_{e}$ distributions around solar maximum over the ESR site exhibit quite different features from those observed at auroral oval latitudes (EISCAT radar) and at midlatitudes (Millstone Hill radar) (Lei et al., 2005), such as the two-peaked distribution of the electron density in winter and at equinox. The daytime density peaks over the ESR appear 1-2 $\mathrm{h}$ later and $10-30 \mathrm{~km}$ higher than that at EISCAT site, in- dicating that $N_{e}$ distributions observed by ESR may not be produced by solar irradiations alone. Plasma dynamic and electrodynamic processes which are characteristic at that latitude may contribute to the special features of electron density in ionospheric the F2-layer.

\subsection{Soft particle precipitation in cusp region}

Particle precipitation has been extensively investigated in the past several decades, with emphasis on particles' spectra and related parameters (e.g. integral energy flux, number flux and characteristics energy). Based on long-term satellite observations, various empirical models of particle precipitating have been established. The widely-accepted models are from Spiro et al. (1982) and Hardy et al. (1985, 1987, 1989). On the basis of FAST observations and EISCAT radar measurements, a new empirical model of auroral precipitating electrons, PEM-2004, has been established by our colleagues at Wuhan University (private communication). One of the agreements among these models is that soft electrons are dominant in the cusp region around magnetic midday. In the cusp region, auroral precipitating electrons usually have high number flux but low energy flux, resulting in low average energy. Around magnetic noon, the ESR radar moves near to the cusp region (Fig. 1). During this time period, an ionospheric ionization enhancement at altitudes around $320 \mathrm{~km}$ has been observed by ESR in all seasons (Fig. 7a, b and c).

Predicted results over the ESR site $\left(75.3^{\circ}\right.$ ILAT) from PEM-2004 under conditions of $100<A E<300 \mathrm{nT}$ are shown in Fig. 8. It is shown that auroral electrons over the ESR site have a maximum number flux with the value of $6.3 \times 10^{8} \mathrm{el} \mathrm{cm}^{-2} \mathrm{~s}^{-1}$ during the magnetic post-noon period (Fig. 8a). The minimum average energy, about $140 \mathrm{eV}$, appears at about 12:00 MLT (Fig. 8b). At magnetic noon (Fig. 8c), the average energy reaches the minimum value of $127 \mathrm{eV}$ at $76.3^{\circ}$ ILAT, which is rather similar to the characteristic energy of soft particles from the magnetosheath.

Millward et al. (1999) numerically simulated the ionospheric effects caused by soft particle precipitation in the cusp region. Ionization rates caused by precipitating electrons with different energies ranging from 100 to $1000 \mathrm{eV}$ are shown in Fig. 9. The simulations imply that electrons with various energies precipitate at different altitudes. Electrons with higher energy can penetrate deeper into the atmosphere, while softer electrons stop at higher altitudes. Auroral electrons with energies of 100 and $200 \mathrm{eV}$ induce the highest ionization rates at altitudes around 360 and $300 \mathrm{~km}$, respectively. According to the calculations of Millward et al. (1999), the characteristics of soft particle precipitation in cusp region are reasonably consistent with the ionization enhancements around $320 \mathrm{~km}$ observed by the ESR.

Note that intense summertime electron density enhancements around magnetic noon have also been reported in recent case studies (Smith et al., 2000; Sims et al., 2005). In a case with southward IMF conditions, Smith et al. (2000) 


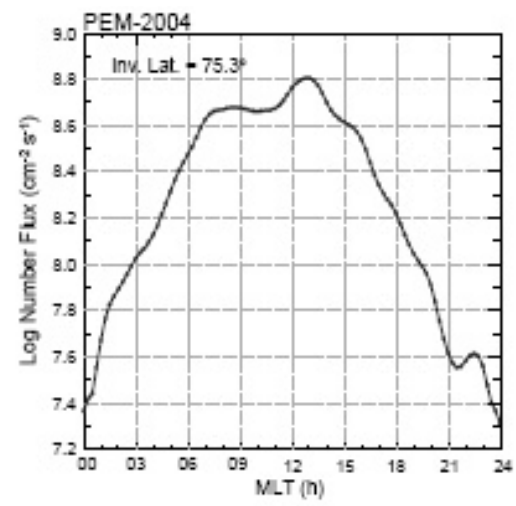

(a)

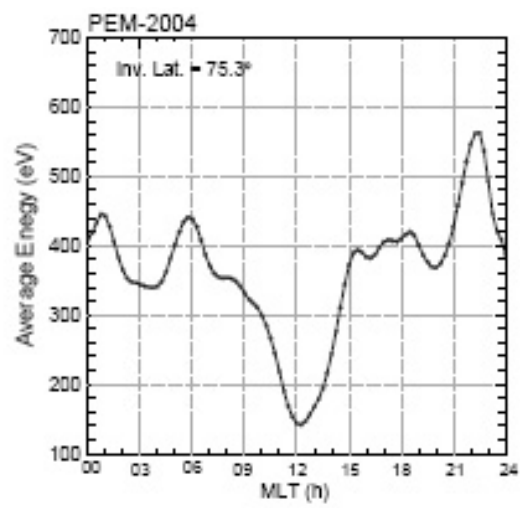

(b)

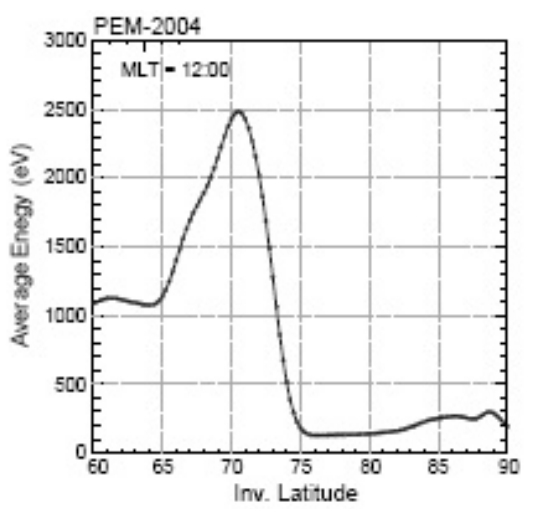

(c)

Fig. 8. Parameters forecasted by PEM-2004 model at the ESR site under conditions of $100<A E<300$ nT. (a) diurnal variation of integral number flux, (b) diurnal variation of average energy, (c) variations of average energy with respect to invariable magnetic latitude at 12:00 MLT.

concluded that the origin of electron density enhancements observed by ESR was soft-particle precipitation in the cusp region. In another event also under southward IMF conditions, however, Sims et al. (2005) argued that plasma convection may play a more important role than soft-particle precipitation in the formation of the summertime Tongue-ofIonization (TOI).

\subsection{Substorms in the winter-time evening sector}

The occurrence of a density peak before magnetic midnight during winter is one of the outstanding features of the $N_{e}$ variations over the ESR site. $N_{e}$ at equinox varies in a similar way, but with its maximum peak in the daytime. Note that the ESR radar was within polar cap during that time period.

In Fig. 8a, it is shown that a minor peak in the number flux of auroral electrons appears around 22:00 MLT, when the corresponding energy exceeds $500 \mathrm{eV}$. According to Fig. 9, an electron precipitation source with such characteristics does not induce a strong ionization enhancement at altitudes around $350 \mathrm{~km}$. At such times, the contribution of solar UV/EUV radiation can also be reasonably neglected. Therefore, the observed enhancement may be attributed to plasma transport processes, which are related to the electric field and neutral wind, including plasma convection and field-aligned transportation, chemical loss process, as well as mass exchanging process between topside ionosphere and magnetosphere.

FUV images from the IMAGE satellite during substorms have also been involved to investigate possible causes for the wintertime ionization enhancement before midnight MLT. Using the list of substorms produced by Frey et al. (2004), we simply compared the mean $N_{e}$ with that observed by the ESR during the relevant time period of each day. A strong correlation was found between the F2-layer ionization enhancement and substorm events, implying a possible relationship

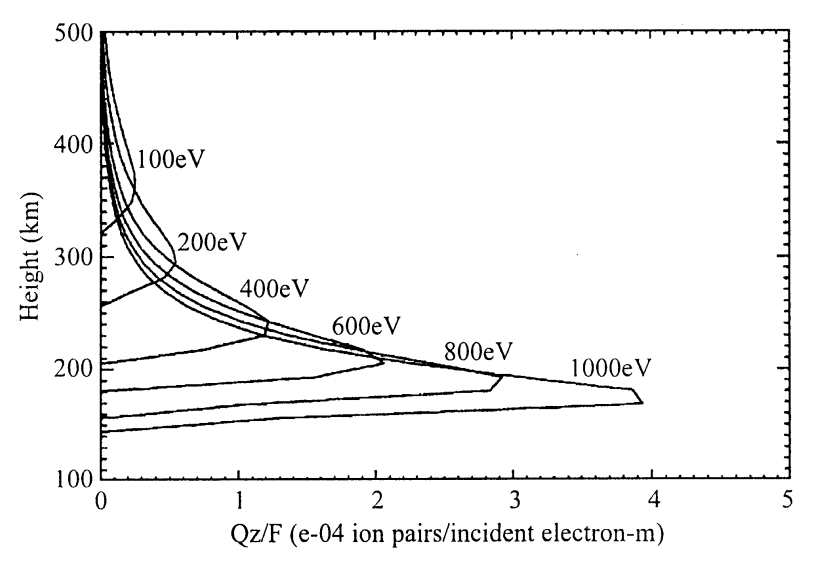

Fig. 9. Ionization production rate caused by precipitating electrons with energies ranging from 100 to $1000 \mathrm{eV}$. (From Millward et al., 1999).

between them. During the substorm expansion phase, the auroral oval extends poleward, and the ionization enhancements caused by particle precipitation may travel towards and be observed by the ESR. This hypothesis seems to be reasonably consistent with the much larger $N_{e}$ fluctuations seen at the ESR (Fig. 7), especially around 20UT in winter, which may indicate the intermittent appearance of such substorm contributions.

Dayside ionization enhancements, transported across the pole in the anti-sunward convection may, however, provide an alterative interpretation of the midnight $N_{e}$ enhancement. Soft-particle precipitation in sub-polar regions has been cited as a possible source for nighttime polar cap ionization, with the less energetic incoming particles giving rise to enhanced density at higher altitudes where the lifetime of plasma is sufficiently long for it to be transported over the polar cap (Weber et al., 1984). Using ground-based optical and digital 
ionosonde measurements and DE-2 observations, Weber and coauthors concluded that the ionospheric structures in the nighttime polar cap F-layer were produced near or equatorward of the dayside auroral zone, and convected across the polar cap in the anti-sunward direction. Using incoherent scatter radar observations, Foster (1993) reported evidences which supported the hypothesis that photoionization convected poleward through the cleft as a source of polarcap ionization. Unfortunately, this hypothesis finds it difficult to explain why the midnight $N_{e}$ concentrations are much higher than the dayside densities observed by ESR fieldaligned beam (see Fig. 7c and f) unless effective and persistent ionization enhancement mechanisms were present during the cross-polar convection of the plasma.

\section{Summary}

A statistical analysis of the seasonal characteristics of electron density in the polar ionospheric F2-layer has been carried out on the basis of long-term EISCAT and ESR observations. Around solar maximum, EISCAT observations show an obvious winter anomaly, but the ESR measurements exhibit no sign of it. Electron densities measured during the daytime at the EISCAT site are generally much higher than the corresponding ESR measurements, especially in winter, and the daytime $N_{e}$ peak at EISCAT lags behind that at ESR by about $1-2 \mathrm{~h}$.

In addition, characteristics of semiannual variation are found at EISCAT around solar minimum, as well as during the falling phase of the solar cycle. During the rising phase, however, the radar observations show no obvious seasonal variations.

For the first time, a prominent wintertime $N_{e}$ peak before magnetic midnight has been observed by the ESR radar. Near equinox, there is a weaker but stable ionization enhancement in almost the same time period. The strong correlation suggested by a preliminary comparison of the EISCAT data with the list of substorms implies that this pre-midnight ionization enhancement may be closely related to substorm events which frequently break out during that MLT sector.

Acknowledgements. EISCAT data were provided by the Max Planck Institute for Solar System Research, and ESR data were obtained through the Madrigal Database. We are grateful to the director and staff of EISCAT for operating the facility and supplying the data. EISCAT is supported by Finland (SA), France (CNRS), Germany (MPG), Japan (NIPR), Norway (NAFN), Sweden (NFS), and the United Kingdom (PPARC). The Authors also thank the two anonymous referees for kind and constructive comments. This work is supported by National Natural Science Foundation of China (No. 40404015) and the open foundation from Key Lab of Geospace Environment and Geodesy, CNEM.

Topical Editor M. Pinnock thanks G. Zastenker for his help in evaluating this paper.

\section{References}

Baron, M. J. and Wand, R. H.: Solar cycle and seasonal variations of the ionosphere observed with the chatanika incoherent scatter radar, Radio Sci., 18, 895-900, 1983a.

Baron, M. J. and Wand, R. H.: F-region ion temperature enhancements resulting from joule heating, J. Geophys. Res., 88, 41144118, $1983 b$.

Farmer, A. D., Crothers, S. R., and Davda, V. N.: The winter anomaly at Troms $\phi$, J. Atmos. Terr. Phys., 52(6-8), 561-568, 1990.

Foster, J.: Storm time plasma transport at middle and high latitudes, J. Geophys. Res., 98, 1675-1689, 1993.

Frey, H. U., Mende, S. B., Angelopoulos, V., and Donovan, E. F.: Substorm onset observations by IMAGE-FUV, J. Geophys. Res., 109, A10304, doi:10.1029/2004JA010607, 2004.

Hardy, D. A., Gussenhoven, M. S., and Holeman, E.: A statistical model of auroral electron precipitation, J. Geophys. Res., 90, 4229-4248, 1985.

Hardy, D. A., Gussenhoven, M. S., and Raistrick, R.: Statistical and functional representation ofthe pattern of auroral energy flux, number flux, and conductivity, J. Geophys. Res., 92, $12275-$ $12294,1987$.

Hardy, D. A., Gussenhoven, M. S., and Brautigam, D.: A statistical model of auroral ion precipitation, J. Geophys. Res., 94, 370392, 1989.

Lei, J. H., Liu, L. B., Wan, W. X., and Zhang, S. R.: Variations of electron density based on long-term incoherent scatter radar and ionosonde measurements over Millstone Hill, Radio Sci., 40(2), RS2008, doi:10.1029/2004RS003106, 2005.

Liu, H. X.: High-latitude ionosphere and its response to magnetic storms, [Ph. D. thesis], Wuhan:School of Electronics Information, Wuhan University, 2001.

Mendillo, M., Rishbeth, H., Roble, R. G., and Wrotena, J.: Modelling F2-lay seasonal trends and day-to-day variability deriven by coupling with the lower atmosphere, J. Atmos.-Sol.-Terr. Phy., 64, 1911-1931, 2002.

Millward, G. H., Rishbeth, H., Fuller-Rowell, T. J., Aylward, A. D., Quegan S. and Moffett R.J.: Ionospheric F2-layer seasonal and semiannual Variations, J. Geophys. Res., 101(A311), 51495156, 1996.

Millward, G. H., Moffett, R. J., Balmforth, H. F., and Rodger, A. S.: Modeling the ionospheric effects of ion and electron precipitation in the cusp, J. Geophys. Res., 104, 24 603-24 612, 1999.

Rishbeth, H.: How the thermoshperic circulation affects the ionospheric F2-layer, J. Atmos. Terr. Phy., 60, 1385-1402, 1998.

Rishbeth H., Muller-Wodarg I.C.F., Zou L., Fuller-Rowell T.J., Millward G.H., Moffett R.J., Idenden D.W. and Aylward A.D.: Annual and semiannual variations in the ionospheric F2-layer. 2, Phys. Discuss., 18, 945-956, 2000a.

Rishbeth H. and Mendillo M.: Patterns of F2-layer variability, J. Atmos. and Solar-terrestrial Phys., 63, 1661-1680, 2001.

Rishbeth, H., Sedgemore-Schulthess, K. J. F., and Ulich, T.: Semiannual and annual variation in the height of the ionospheric F2peak, Ann. Geophys., 18, 285-299, 2000b.

Rishbeth, H. and Setty, C. S. G. K.: The F-layer at sunrise, J. Atmos. Terr. Phy., 21, 263-276, 1961.

Shen, C. S., Zi, M. Y., Wang, J. S., Liu, S. L., and Xu, J. Y.: The features of $f_{0} F_{2}$ at Zhongshan station of Antarctica, Chinese J. Polar Research, 15(3), 186-194, 2003. 
Sims, R. W., Pryse, S. E., and Denig, W. F.: Spatial structure of summertime ionospheric plasma near magnetic noon, Ann. Geophys., 23, 25-37, 2005, http://www.ann-geophys.net/23/25/2005/.

Smith, A. M., Pryse S. E., and Kersley, L.: Polar Patches observed by ESR and their possible origin in the cusp region, Ann. Geophys., 18, 1043-1053, 2000, http://www.ann-geophys.net/18/1043/2000/.

Spiro, R. W., Reiff, P. H., and Maher Jr., L. J.: Precipitating electron energy flux and auroral zone conduc- tances -An empirical model, J. Geophys. Res., 87, 8215-8227, 1982.

Yonezawa, T. and Arima, Y.: On the seasonal and non-seasonal annual variations and the semi-annual variation in the noon and midnight electron densityes of the F2-layer in middle latitudes, J. Radio Res. Lab., 6(25), 293-309, 1959.

Yonezawam, T.: The solar-activity and latitudinal characteristics of the seasonal, non-seasonal and semi-annual variations in the peak electron densities of the F2-layer at noon and at midnight in middle and low latitudes, J. Atmos. Terr. Phy., 33, 889-907, 1971.
Weber, E., Buchau, J., Moore J., Sharber J. R., and Livingston, R. C.: F-layer ionization patches in the polar-cap, J. Geophys. Res., 89, 1683-1694, 1984.

Zhu, M. H., Cao, C., and Wu, J.: Analyses of Ionospheric Properties over Zhongshan station Antarctica, Chinese J. Radio Sci., 11(1), 96-101, 1996.

Zhu, M. H., Cao, C., and Wu, J.: The effects of low energy electron precipitation on the ionosphere over Zhongshan station, Antarctica, Chinese J. Polar Research, 10(1), 31-36, 1998.

Zou, L., Rishbeth, H., Muller-Wodarg, I. C. F., Aylward, A. D., Millward, G. H., Fuller-Rowell, T. J., Idenden, D. W., and Moffett, R. J.: Annual and semiannual variations in the ionospheric F2-layer. 1. Modelling, 18, 927-944, 2000. 